\title{
Computational study of substrates and mediators features of lacasses
}

\author{
Azar Delavari ${ }^{1}$, Margarita Calafell ${ }^{2}$ and Juan J. Perez ${ }^{1}$ \\ ${ }^{1}$ Department of Chemical Engineering. Universitat Politècnica de Catalunya \\ 08028 Barcelona, Spain \\ ${ }^{2}$ BIPROCEL, Institut Politècnic del Campus de Terrassa, crta. N-150, km 14,5 \\ Terrassa, 08227
}

\begin{abstract}
Laccases are enzymes of the family of the multicopper oxidases, being widely used for biotechnological applications. The enzyme catalytic cycle consists in the oxidation of the substrate with the concomitant reduction of molecular oxygen to water. In the process the substrate is converted to a free radical, that can oxidize larger substrates acting as a mediator or it can undergo polymerization. Substrate binding is not specific and there is a large diversity of substrates for laccases. Moreover, the binding site shows important differences among diverse species. The goal of the present work is to characterize the laccase binding pocket of different species in order to establish their common pharmacophoric characteristics. For this purpose we have carried out docking studies with a subset of substrates, covering the diversity of substrates using the Glide program. We have also analyze the characteristics of the binding site using diverse probes. We further have rationalized the differential values of $\mathrm{Km}$ found among diverse species for a specific substrate. Finally, special attention has been devoted to the binding of the mediator 2,2'-azido-di-(3-ethylbenzothiazoline)-6sulfonic acid (ABTS), commonly used in industrial processes.
\end{abstract}

\section{INTRODUCTION}

Laccases (EC 1.10.3.2) are oxidoreductases of the family of the multicopper oxidases, being widely used for biotechnological applications [1]. The enzyme has been used for biotransformation and decolorization of dyes, pulp delignification, oxidation of organic pollutants, microbial transformation of natural products, and the development of biosensors or biofuel cells.

These enzymes catalyze the reduction of oxygen to water:

$$
\mathrm{O}_{2}+4 \overline{\mathrm{e}}+4 \mathrm{H}^{+} \rightarrow 2 \mathrm{H}_{2} \mathrm{O}
$$

The anodic reaction consists of the oxidation of the substrate to a free radical, providing the necessary electrons for the subsequent reduction of oxygen. In turn, the radical produced may oxidize larger substrates, acting as a mediator or even it can undergo polymerization.

Substrate binding is not specific with a large diversity of substrates so far identified. Moreover, the binding site shows important differences among diverse species. The goal of the present work is to characterize the laccase binding pocket of fungal and bacterial laccases in order to establish their common pharmacophoric characteristics. For this purpose we have carried out docking studies of several substrates including: 2,2'-azido-di-(3-ethylbenzothiazoline)-6-sulfonic acid (ABTS), xylidine, 2,2,6,6-tetramethyl-piperidine-1-oxyl radical (TEMPO), 1- 
hydroxybenzotriazole (HBT), N-hydroxyphthalimide (HPI), 3-hydroxyantranilic acid, 4-hydroxybenzoic acid, 2,6-dimethoxyphenol, phenolsulfonphthalein also known as phenol red, acetosyringone, vanillin, acetovanillone, sinapic acid and, p-coumaric acid, shown in Figure 1.
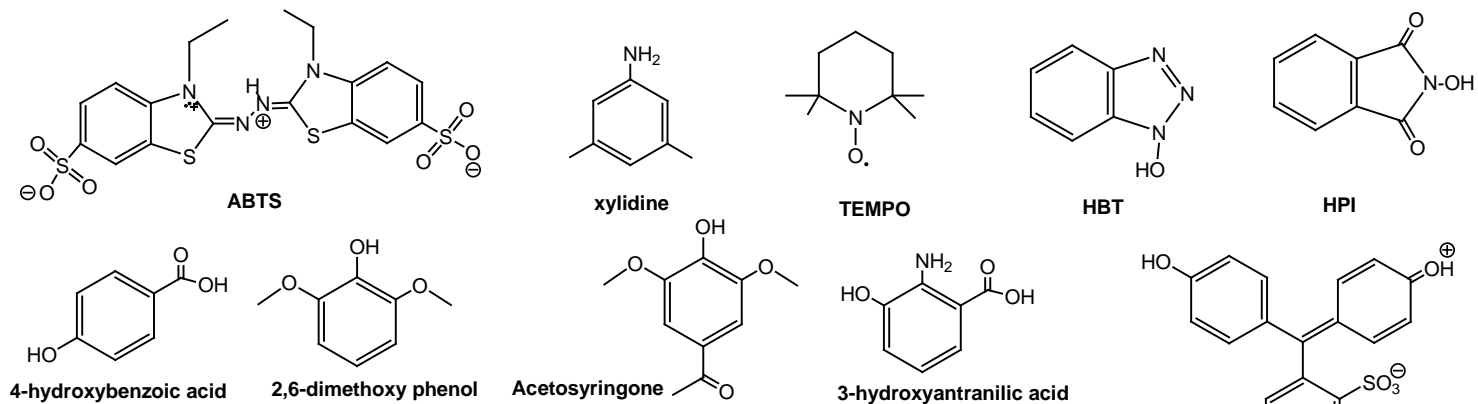<smiles>COc1cc(C=O)ccc1O</smiles><smiles>COc1cc(C(C)=O)ccc1O</smiles>

Vanillin

Acetovanillone

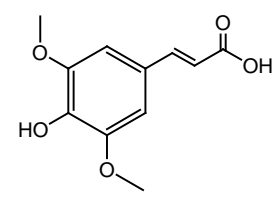<smiles>O=C(O)/C=C/c1ccc(O)cc1</smiles><smiles>O=[S-]1C=CC(=C(c2ccc(O)cc2)c2ccccc2[OH2+])C=C1</smiles>

phenol red

Figure 1. Chemical structures of the substrates studied in the present work.

\section{METHODS}

Docking studies were performed using the crystallographic substrate-enzymes complex structures of fungal laccase bound with xylidine (pdb ID: 1KYA) and the bacterial lacasse bound with ABTS (pdb ID: 1UVW), retrieved from the protein data bank. Water molecules were removed from the structures and hydrogens added. Structures were subsequently energy minimized using the parm99SB force field embedded in the AMBER force field [2].

Geometry of the substrates was optimized using DFT method with a 6-31G* basis set. Special case was devoted to ABTS since the crystallographic structure does not provide information of its protonation state. Accordingly, optimization of $\mathrm{ABTS}^{2-}$, $\mathrm{ABTS}^{1-}$ and ABTS were carried out.

Substrates were docked on the minimized structures around the T1 region using the Glide program [3].

\section{RESULTS}

Comparison of the optimized structures of $\mathrm{ABTS}^{2-}, \mathrm{ABTS}^{1-}$ and ABTS with the bound structure found in the crystallographic structure (pdb ID: 1UVW) suggest that the ligand binds when doubly protonated on the bridge nitrogens. In order to give support to this hypothesis we experimentally determined the pKa of ABTS. Titration curves show that ABTS exhibit two pKa at 1.5 and 9.5, respectively and consequently at the working $\mathrm{pH}$ of around 4, the nitrogens will be protonated.

The binding pockets were characterized using different interaction probes, including a hydrophobic, proton accepting and proton donating using the MOE program 
[4]. Analysis of these studies reveals that binding pocket in fungal laccase is smaller than the corresponding to the bacterial one. Moreover, the binding site of the fungal is more hydrophobic.

Analysis of the complexes permits to identify those residues involved in ligand binding. In the case of the fungal lacasse residues Phe162, Phe265, Phe337, Gly392, Leu164, Pro391, Asp206, His458, His419 define the binding pocket, whereas residues Gly417, Thr415, Arg416, Pro226, Pro384, Leu386, His497, His419 define the biding pocket in bacterial laccase. Moreover, docking studies suggest that the ligands interact via a hydrogen bond with His458 in the case of the fungal and His497 in the case of the bacterial laccases, involved in the coordination with copper in the T1 site. In the case of the fungal lacasse there is Asp206 assisting to the binding of the substrate. Figures 2a and $2 \mathrm{~b}$ shows ABTS bound to the fungal and bacterial laccases showing the residues involved in binding.

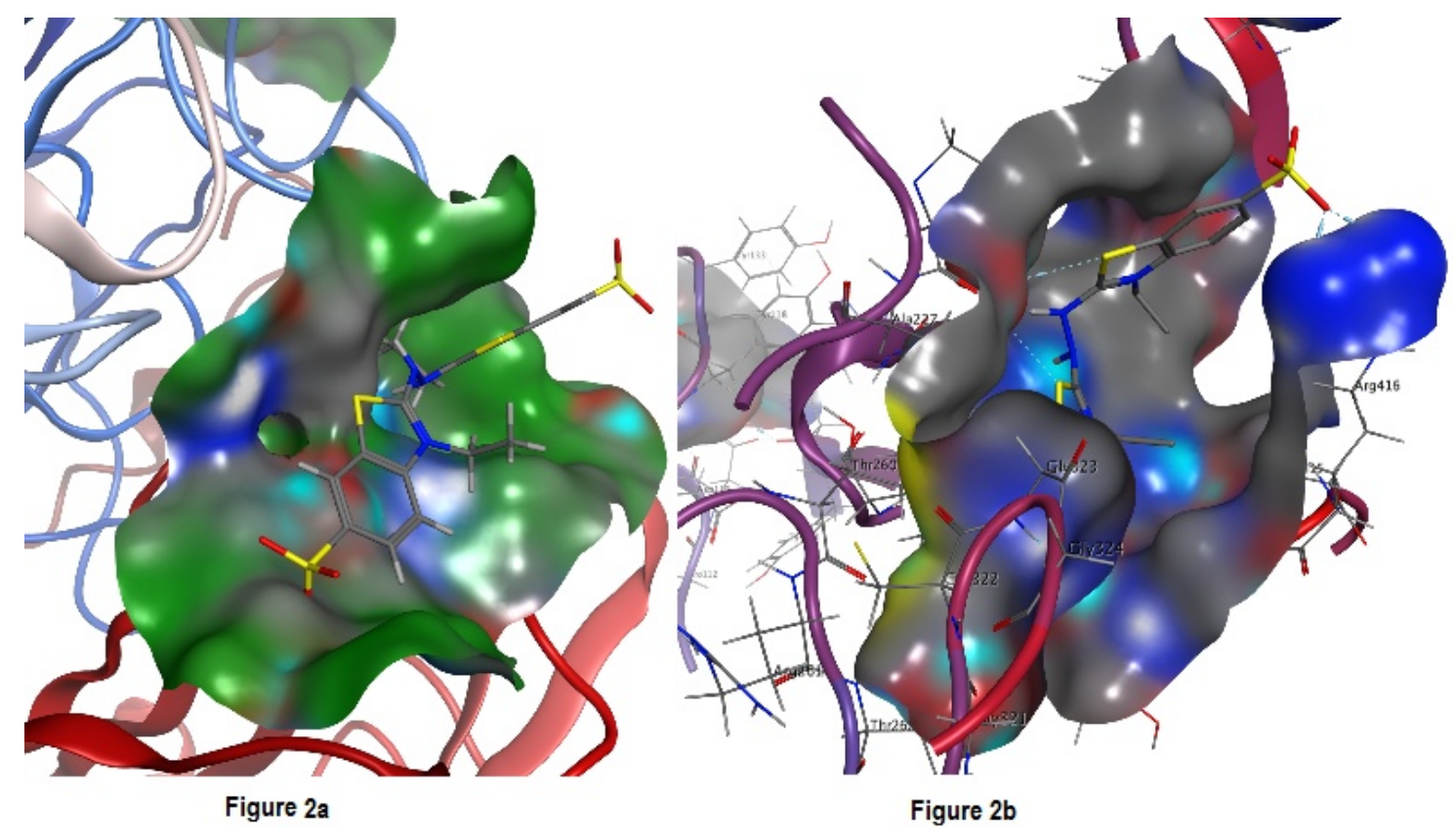

Figure 2. a) ABTS bound to the fungal laccase. B) ABTS bound to the bacterial laccase

\section{CONCLUSIONS}

We have studied the characteristics of the binding pocket of fungal and bacterial laccases. The former is larger and more hydrophobic and the latter. Moreover, the residues involved in substrate binding have also been identified. Finally, these studies support that ABTS binds in its double protonated form at the working $\mathrm{pH}$ of the enzyme around 4 .

\section{ACKNOWLEDGEMENTS}

The authors wish to express their gratitude to Natalie Lorin and Christian Åsheim for sharing their measurements on the $\mathrm{pK}_{\mathrm{a}}$ of ABTS. 


\section{RFERENCES}

1. A. I. Canas \& Camarero, S. (2010). Laccases and their natural mediators:

Biotechnological tools for sustainable eco-friendly processes. Biotechnol. Adv. 28, 694705

2. D.A. Case, T.A. Darden, T.E. Cheatham, III, C.L. Simmerling, J. Wang, R.E. Duke, R. Luo, R.C. Walker, W. Zhang, K.M. Merz, B. Roberts, S. Hayik, A. Roitberg, G. Seabra, J. Swails, A.W. Goetz, I. Kolossváry, K.F. Wong, F. Paesani, J. Vanicek, R.M. Wolf, J. Liu, X. Wu, S.R. Brozell, T. Steinbrecher, H. Gohlke, Q. Cai, X. Ye, J. Wang, M.-J. Hsieh, G. Cui, D.R. Roe, D.H. Mathews, M.G. Seetin, R. Salomon-Ferrer, C. Sagui, V. Babin, T. Luchko, S. Gusarov, A. Kovalenko, and P.A. Kollman (2012), AMBER 12, University of California, San Francisco.

3. R.A. Friesner, Banks, J.L., Murphy, R.B., Halgren, T.A., Klicic, J.J., Mainz, D.T., Repasky, M.P., Knoll, E.H., Shelley, M., Perry, J.K., Shaw, D.E., Francis, P. \& Shenkin, P. (2004). Glide: A New Approach for Rapid, Accurate Docking and Scoring. 1. Method and Assessment of Docking Accuracy. J Med Chem 47,1739-1749

4. Vilar, S., Cozza, G., Moro, S. (2008) Medicinal chemistry and the molecular operating environment (MOE): application of QSAR and molecular docking to drug discovery. Curr. Top. Med. Chem., 8, 1555-1572. 